\section{Evidence into practice}

\author{
Application of psychological models of change \\ in evidence-based implementation
}

\author{
RUPATHARSHINI CHILVERS, GLYNN HARRISON, ATTILA SIPOS \\ and MADELINE BARLEY
}

Psychiatrists have long recognised that routine clinical practice needs to be shaped and informed by external evidence (Lewis, 1958). Psychiatric researchers were among the first to utilise multi-centre randomised controlled trials (demonstrating the effectiveness of antipsychotics), and psychologists were among the first in the health field to develop techniques of metaanalysis. Social workers, too, point to their tradition with the publication of one of the earliest controlled trials (Lehrman, 1949).

Despite these early achievements by mental health professionals, there remain significant gaps between routine care and the current state of evidence. For example, in the UK, as elsewhere, the slow uptake of psychoeducational interventions for schizophrenia demonstrates the difficulties experienced by health care providers in developing coordinated training and organisational responses to new knowledge. The Schizophrenia Patient Outcomes Research Team (PORT) studies (Lehman et al, 1998) carried out in the USA also demonstrated significant shortfalls in clinician conformance across a range of evidence-based recommendations for the management of schizophrenia, and routine audits continue to report prescribing of inappropriately high doses of neuroleptics. Such findings have led to the exploration of new strategies for the dissemination and implementation of research findings and complex interventions to effect clinician behaviour change. But what has been achieved and how good is the evidence that they work?

\section{DISSEMINATION $v$. IMPLEMENTATION}

There has been extensive growth in the passive dissemination of research findings in recent years: examples in the UK include the National electronic Library for Health, the National Institute for Clinical Excellence and, internationally, the Cochrane Collaboration. It is now widely recognised, however, that simple diffusion and passive dissemination of information are largely ineffective at changing practice (NHS Centre for Reviews and Dissemination, 1999). Mason et al (1999a) report an interrupted time series measure of the impact of recommendations in the Effective Health Care Bulletin that there were no additional benefits to using the newer antidepressants within primary care (NHS Centre for Reviews and Dissemination, 1993). Despite some evidence of clinician response, the attempt to change behaviour across the board was disappointing and the upward trend in the use of the newer antidepressants continued.

Implementation (as opposed to dissemination) strategies, on the other hand, have shown promise. Here, a more systematic and participatory approach is employed. Interventions such as face-to-face educational outreach visits (academic detailing) to individual practitioners and to teams, computerised and manual reminders about new information and interactive educational meetings show some evidence of effectiveness (NHS Centre for Reviews and Dissemination, 1999). Evidence generally suggests that multi-faceted interventions combining two or more strategies are more likely to result in favourable change in practice than single interventions (Wensing et al, 2000). There is still a relative lack of robust research in this area, however, and the methodological quality of existing studies is frequently poor (Mason et al, 1999b). In particular, interventions often are inadequately described, hampering the identification of critical components that predict success or failure. With interventions already evaluated having, at best, a relatively modest effect on practice, there is a long way to go in understanding the processes and models that effect changes in professional practice.

\section{MODELS OF CHANGE}

To learn how to influence the behaviour of clinicians, it may be useful to examine models that have been developed to motivate change in the behaviour of their patients, especially in the field of addiction. The 'stages of change' (transtheoretical) model proposed by Prochaska \& Di Clemente (1983) was used initially within the field of drug and alcohol misuse but has had a significant impact on health promotion initiatives in a range of settings and problem areas. Applications include the promotion of healthy diets in the workplace, encouraging regular exercise patterns and smoking cessation. The resulting model (see Fig. 1) describes change as a continuous process in which participants move through stages of pre-contemplation, contemplation, decision, active change and maintenance. The model enables the 'change agent' to tailor information and support according to the individual's (or group's) stage of readiness, with the cumulative effect producing a permanent behavioural change. Although initially devised to motivate behavioural change in patients, could this model be developed further to motivate doctors in getting research into practice?

The pharmaceutical industry clearly has achieved considerable success in shaping clinician behaviour (Wazana, 2000) and may have something to teach us. For instance, in the 1980s, Eli Lilly increased prescriptions of benoxaprofen in the UK from 2000 to 55000 a week (Nelkin, 1986). Although companies doubtless would highlight the self-marketing quality of their products, in practice they harness a range of behaviour modification techniques targeted at clinicians. The most familiar technique is the deployment of representatives making direct contact with clinicians. It has been estimated that up to $60 \%$ of promotional budgets is spent on representatives and executive accounts (Lexchin, 1988). These visits have similarities to 'academic detailing' or educational outreach visits but utilise a marketing approach. The visits incorporate a range of additional interventions, such as quotation of 'opinion leaders', reminders printed on gifts having high desk-top visibility and behavioural reinforcers in the form of rewarding conference venues where socially mediated behavioural modification can take place. These participatory and multi-faceted approaches appear to be based on a theoretical and conceptual framework for 


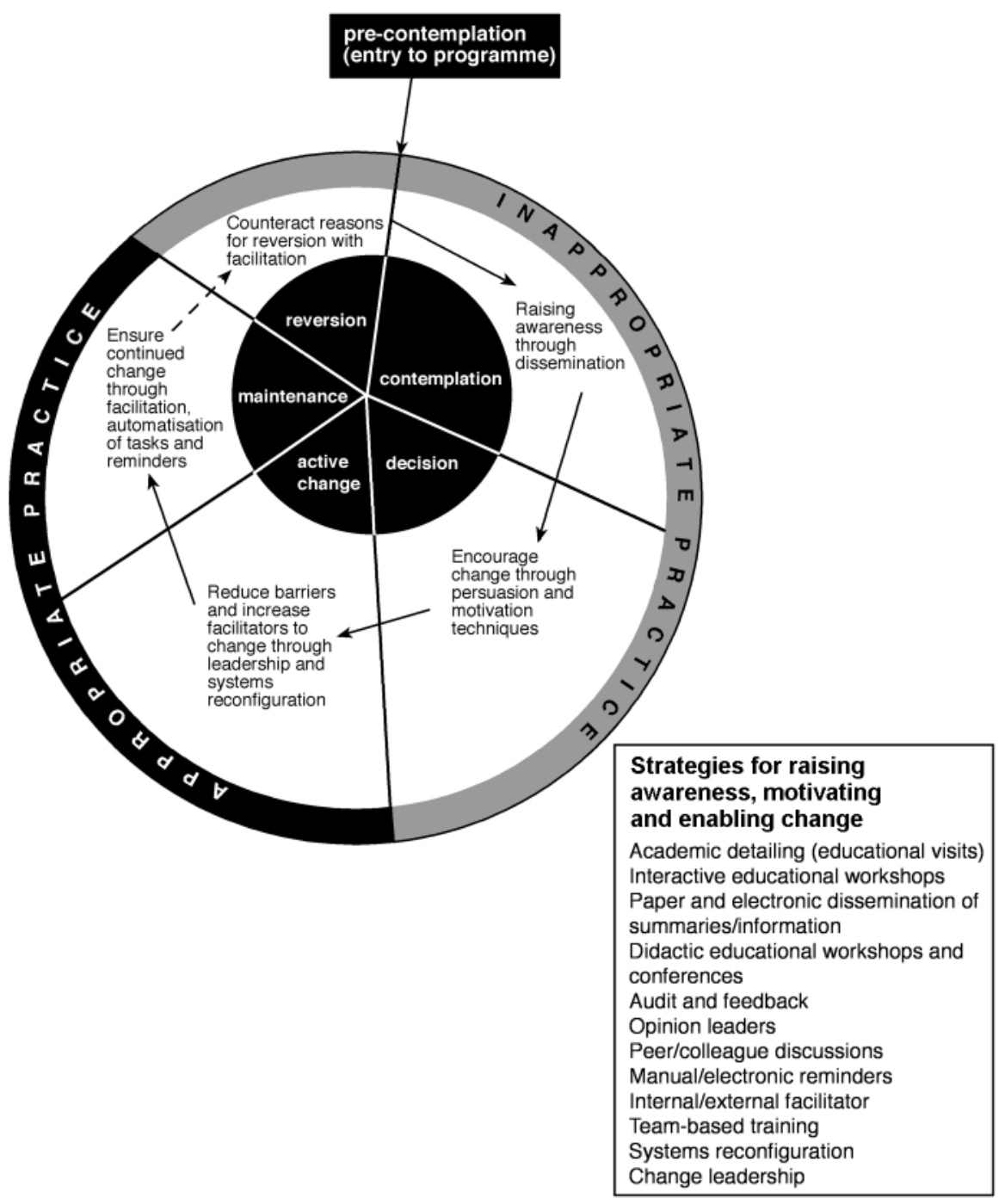

Fig. I A 'stages of change' model.

changing clinician behaviour described by Lidstone (1987). Writing for pharmaceutical companies, Lidstone conceptualises 'stages of change' that a clinician needs to be moved along: unawareness, awareness, interest, evaluation, trial, usage and continued usage. Although gifts and other motivators are appropriate, Lidstone considers the two most effective interventions (at any stage of the process) to be face-to-face visits from representatives and 'educational' meetings.

\section{'REPRESENTATIVES' FOR EVIDENCE-BASED PRACTICE}

Could similar, but non-marketing, techniques be used to promote evidence-based practice and to accelerate individual and would be unlikely to produce sustained change in the absence of further interventions to motivate the move to the decision stage. The role of individual educational visits (academic detailing) across all stages could be a powerful intervention within this conceptual framework, owing to their potentially interactive, supportive and reinforcing nature. This would be closely analogous to a visit from a pharmaceutical industry representative, but here the interaction would be aimed at promoting evidence-based practice for a set of target conditions or clinician behaviour. The approach would be motivational rather than marketing and would seek to accommodate clinician judgement and patient preference into the application of emerging evidence.

Advocates of a 'stages of change' framework within clinical practice face three main challenges. First, there is a relative paucity of outcome trials indicating the effectiveness of interventions based on the stages of change for patients, let alone for its use in clinicians (Whitelaw et al, 2000). Second, there appears to be no standardised measure that can be utilised or adapted readily to categorise a clinician's stage of change or readiness for change - a state of play that is still apparent within the health promotion and addiction literature (see Bunton et al, 2000). Third, although the model recognises the impact of the environment in which the behaviour takes place, professional behaviour characteristically occurs within an organisational setting that is beyond the control of the individual clinician. This is especially relevant to treatments other than prescribing, which require skills transfer and teambased initiatives. Initiatives promoting change at the organisational level that take into account structures, social factors, physical setting, technology and leadership have been shown to produce positive outcomes within the field of organisational development (see Porras \& Robertson, 1992), and need to be incorporated within the 'stages of change' model.

Although many health care providers have established 'Getting Research Into Practice' groups and committees, there is a challenging research agenda ahead for how this can be achieved practically. The 'stages of change' (transtheoretical) model provides a useful theoretical framework in a field where there are currently no 'magic bullets'. But if we are to begin to match the skill and effectiveness of the pharmaceutical industry in shaping clinician 
behaviour, we need more resources, greater imagination and, above all, more evidence about what works.

\section{DECLARATION OF INTEREST}

Glynn Harrison and Attila Sipos have received financial support from pharmaceutical companies to attend educational meetings. Glynn Harrison has received fees for making educational contributions to meetings sponsored by pharmaceutical companies.

\section{REFERENCES}

Bunton, R., Baldwin, S., Flynn, D., et al (2000) The 'stages of change' model in health promotion: science and ideology. Critical Public Health, 10, 55-70.

Cohen, S. J., Halvorson, H.W. \& Gosselink, C. A.

(1994) Changing physician behaviour to improve disease prevention. Preventative Medicine, 23, 284-291.

Lehman, A. F., Steinwachs, D. M., Dixon, L. B., et al (1998) Patterns of usual care for schizophrenia: initial results from the Schizophrenia Patient Outcomes Research Team (PORT) Client Survey. Schizophrenia Bulletin, 24, II-20.

Lehrman, L. J. (1949) Successes and failure of treatment of children in guidance clinics of the Jewish Board of Guardians. Research Monographs, I, I-87.

Lewis, A. (1958) Between guess work and uncertainty in psychiatry. Lancet, I, I7I-175.

RUPATHARSHINI CHILVERS, MSc, GLYNN HARRISON, FRCPsych, ATTILA SIPOS, MRCPsych, MADELINE BARLEY, BSc, Division of Psychiatry, University of Bristol, Bristo

Correspondence: Rupa Chilvers, Division of Psychiatry, University of Bristol, Cotham House, Cotham Hill, Bristol BS6 6JL, UK

First received 8 August 200I, final revision 19 November 200I, accepted 2I November 200I)

Lexchin, J. (1988) Pharmaceutical promotion in New Zealand. Community Health Studies, 12, 264-272.

Lidstone, J. (1987) Marketing Planning for the Pharmaceutical Industry. Brookfield, VT: Gower.

Mason, J., Freemantle, N. \& Young, P. (1999a) The effect of the distribution of Effective Health Care bulletins on prescribing selective serotonin reuptake inhibitors in primary care. Health Trends, 30, 120-122.

\section{_ ,Wood, J. \& Freemantle, N. (1999b) Designing} evaluations of interventions to change professional practice. Journal of Health Services Research and Policy, $\mathbf{4}$, $44-48$.

Nelkin, D. (1986) How to doctor the media. New Scientist, II2, 5I-56.

NHS Centre for Reviews and Dissemination (1993) The treatment of depression in primary care. Effective Health Care, I, March.

- (1999) Getting evidence into practice. Effective Health Care, 5, February.

Porras, J. \& Robertson, P. (1992) Organisation development. In Handbook of Industrial and
Organisational Psychology (eds M. Dunnette \& L. Hough) pp. 719-822. London: Consulting Psychologists Press.

Prochaska, J. O. \& Di Clemente, C. C. (1983) Stages and processes of self-change of smoking: toward an integrative model of change. Journal of Consulting and Clinical Psychology, 5, 390-395.

Wazana, A. (2000) Physicians and the pharmaceutical industry: is a gift just a gift? Journal of the American Medical Association, 283, 373-379.

Wensing, M., Laurant, M., Hulscher, M., et al (2000) Methods for identifying barriers and facilitators for implementation. In Changing Professional Practice: Theory and Practice of Clinical Guidelines Implementation (eds T. Thorsen \& M. Makela), pp. II9-131. Copenhagen: Danish Institute for Health Services Research and Development.

Whitelaw, S., Baldwin, S., Bunton, R., et al (2000) The status of evidence and outcomes in Stages of Change research. Health Education Research, 15 , 707-718. 